\title{
A DIVERSIDADE NAS IMAGENS DOS MANUAIS DO PROFESSOR DE EDUCAÇÃO FÍSICA NO BRASIL
}

\author{
DIVERSITY IN THE IMAGES OF PHYSICAL EDUCATION TEACHER \\ MANUALS IN BRAZIL C P
}

LA DIVERSIDAD EN LAS IMÁGENES DE LOS MANUALES DEL PROFESOR DE EDUCACIÓN FÍSICA EN BRASIL C己

doi' https://doi.org/10.22456/1982-8918.112065

(iD) Alexandre Paulo Loro* <alexandrepauloloro@yahoo.com.br>

(D) Irene Moya-Mata** <irene.moya@uv.es>

(D) Alexandra Valencia-Peris** <alexandra.valencia@uv.es>

Meire Aparecida Lóde Nunes*** <meirelode@gmail.com>

José Devís-Devís** <jose.devis@uv.es>

\footnotetext{
*Universidade Federal da Fronteira Sul. Chapecó, SC, Brasil.

**Universidade de Valência. Valência, Espanha

***-Universidade Estadual do Paraná. Curitiba, PR, Brasil.
}

\begin{abstract}
Resumo: A imagem é uma linguagem icônica com o poder de transmitir informações, reproduzir estereótipos e influenciar o professor. Este estudo trata dos manuais do professor de Educação Física elaborados no Brasil e aprovados no Programa Nacional do Livro e do Material Didático (BRASIL, 2017). Especificamente, analisa as imagens de pessoas neles existentes, com vistas a verificar se existem estereótipos relacionados às práticas corporais. Foi realizada a análise com 854 imagens por meio dos testes de Xis ao Quadrado de independência que revelaram estereótipos relacionados às práticas corporais. Os resultados mostram a predominância de grupos mistos de crianças, com corpos ectomorfos, de cor ou raça branca e sem deficiência. Embora a diversidade de sexos esteja representada, os materiais ainda favorecem a reprodução de estereótipos e grupos hegemônicos tradicionais, perpetuando a invisibilidade da diversidade de corpos, de cor ou raça e de pessoas com deficiência.
\end{abstract}

Palavras chave: Materiais de ensino. Educação Física. Imagem Corporal. Diversidade cultural.
Recebido em: 11-03-2021 Aprovado em: 04-08-2021 Publicado em: 18-09-2021

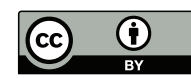

Este é um artigo publicado sob a licença Creative Commons Atribuição 4.0 Internacional (CC BY 4.0). eISSN: 1982-8918 


\section{INTRODUÇÃO}

De acordo com um Relatório Europeu, produzido a partir de uma pesquisa com professores (CACHIA; FERRARI, 2010), constatou-se que o livro didático atualmente é o material curricular mais utilizado nas escolas europeias, atingindo $85 \%$ de uso no ensino obrigatório dos 27 países estudados. Esse tipo de material é uma alternativa de desenvolvimento curricular e profissional também em países não europeus, inclusive está em expansão na Educação Física brasileira. Isso é indicado pela recente aparição do manual do professor de Educação Física para Anos iniciais da Educação Básica no Programa Nacional do Livro e do Material Didático (BRASIL, 2017), com atribuição de tematizar "as práticas corporais em suas diversas formas de codificação e significação social, entendidas como manifestações das possibilidades expressivas dos sujeitos e patrimônio cultural da humanidade", conforme determina a Base Nacional Comum Curricular (BRASIL, 2018, p. 171).

No Brasil, o tema é pouco investigado na área da Educação Física. Loureiro e Moreira (2020) apresentam um balanço da produção acadêmica dos Livros Didáticos de Educação Física (LDEF), composta por artigos, trabalhos de conclusão de curso, dissertações e teses. A partir do questionamento acerca do uso de livros ao longo da história dessa disciplina escolar no Brasil, constataram que a primeira fonte encontrada é de 1993, sendo produzidos apenas 55 pesquisas até 2019. Identificaram, ainda, a partir das pesquisas que compõem o estudo, 19 LDEF entre o período de 1855 a 2014. Para Amaral et al. (2021, p. 126), investigações acerca dos "textos didáticos na área da Educação Física" se fazem pertinentes em decorrência da importância que assumem na prática pedagógica e à escassez de literatura na área.

Em outro estudo recente, Silva et al. (2020) analisaram artigos, livros e documentos (período de 2014 a 2019) que apresentavam como tema principal o PNLD no contexto do Ensino Fundamental do Componente Curricular de Educação Física. A partir da análise de literatura, os autores constataram que são incipientes as pesquisas sobre o tema, bem como a sua relação com a BNCC, possivelmente em decorrência da Educação Física não estar presente no PNLD até o ano de 2019.

Ante o exposto, a perspectiva imposta pela BNCC nos manuais do professor de Educação Física leva-nos a refletir sobre que tipo de currículo está sendo transmitido e a indagar a instrumentalização metodológica de transmissão cultural, pois essas informações serão assimiladas pelos professores e, posteriormente, refletidas/ reproduzidas em seus alunos, com potencialidade para representar a diversidade, bem como para a criação ou rompimento de estereótipos.

A importância de focar na diversidade exposta nas imagens dos materiais curriculares impressos revela-se pela própria multiculturalidade da sociedade brasileira, implícita no contexto da Educação Física Escolar. A diversidade, em um sentido mais amplo, "[...] é resultado de um processo relacional, histórico e discursivo de construção da diferença" (SILVA, 1999, p. 10); em um sentido mais restrito, a preocupação em atender à diversidade dos alunos constitui não apenas uma das características do novo modelo de currículo, mas também uma questão-chave na abordagem geral das estruturas curriculares. 
A análise das imagens nos livros didáticos justifica-se também por serem portadoras do chamado currículo oculto. No contexto educacional, as informações podem ser transmitidas de duas maneiras: através de um discurso explícito e/ou através de um discurso implícito. Conceitualmente, "O currículo oculto pode ser definido como o conjunto de conteúdos transmitidos implicitamente em um contexto educacional" (ACASO; NUERE 2005, p. 208), com o objetivo de perpetuar um conjunto de conhecimentos que não seria apropriado tratar de forma evidente no contexto educacional, como o posicionamento central em termos de sistemas de compartilhamento de poder, o alinhamento com uma classe social específica, bem como a defesa de uma cor ou raça ${ }^{1}$, um gênero, uma cultura e uma religião sobre os outros.

Neste estudo, portanto, reportamo-nos à classificação dos materiais curriculares impressos proposta pelos pesquisadores espanhóis Molina-Alventosa, Devís-Devís e Peiró-Velert (2008), considerando o caráter sociocrítico da pesquisa (DEVÍS-DEVÍS, 2012). Nessa perspectiva, o presente estudo trata sobre os manuais do professor de Educação Física elaborados no Brasil e aprovados no Programa Nacional do Livro e do Material Didático (BRASIL, 2017), especificamente em relação às imagens de pessoas neles existentes, com vistas a verificar se existem estereótipos relacionados às práticas corporais.

\section{MATERIAIS CURRICULARES IMPRESSOS}

Os materiais curriculares, concebidos em sentido amplo, acomodam diversos materiais que intervêm no processo de ensino-aprendizagem da Educação Física Escolar. Isto quer dizer que contemplam instrumentos ou objetos utilizados no contexto escolar como mediadores do processo ensino-aprendizagem, pois facilitam a transição de uma situação de ensino para uma situação de aprendizagem, manifestando o envolvimento nesse processo entre alunos e professores, mas também de outros subsistemas configurados, como política, gestão educacional ou editoras.

No interior dos projetos educacionais, os materiais curriculares adquirem significado, sendo possível extrair quatro características fundamentais em sentido amplo: a) é qualquer instrumento ou objeto usado no contexto escolar; b) é utilizado com a intenção de comunicar conteúdo ou favorecer ou orientar o processo de ensinoaprendizagem; c) seu uso é estabelecido dentro de algumas práticas relacionadas ao desenho, desenvolvimento, avaliação ou justificativa do currículo; e d) representa uma conexão tangível com uma teoria curricular específica (MOLINA-ALVENTOSA, 2015).

A análise de livros didáticos de Educação Física, enquanto material curricular, aumentou na última década sobre diferentes aspectos. Foram realizadas análises do discurso de materiais curriculares impressos (ROSSI et al., 2009; MUNKSVENDSEN; TINGGAARD-SVENDSEN, 2016; JANEMALM; QUENNERSTEDT; BARKER, 2019) e também das imagens contidas nos textos (MOYA-MATA; ROS;

1 Classificação utilizada pelo Instituto Brasileiro de Geografia e Estatística (IBGE). Diponível em: https://www.ibge. gov.br. Acesso em: 04 ago. 2021. 
BASTIDA; MENESCARDI, 2013; GONZÁLEZ-PALOMARES; ALTMANN; REY-CAO, 2015; MARTÍNEZ-BELLO; MOLINA-GARCÍA, 2016; GONZÁLEZ-PALOMARES; TÁBOAS-PAIS; REY-CAO, 2017; SÁNCHEZ-HERNÁNDEZ; MARTOS-GARCÍA; LÓPEZ-NAVAJAS, 2017; MOYA-MATA; RUIZ-SANCHIS; MARTIN-RUIZ; ROS 2019a).

Os estudos demonstram a potencialidade de pesquisas sobre o livro didático na Educação Física, revelando a proliferação de diversas abordagens possíveis para o estudo destes elementos tradicionais da tecnologia educativa, os quais poderão estar imbuídos potencialmente de inovação (DEVíS-DEVís et al., 2001), assim como possibilitar o aprofundamento de vários aspectos da educação escolar e de sua história (MUNAKATA, 2012).

Entre as principais linhas de pesquisa destacam-se os estudos crescentes sobre a análise (MUNK-SVENDSEN; TINGGAARD-SVENDSEN, 2016; MOYA-MATA et al., 2017; MOYA-MATA; RUIZ-SANCHIS; MARTIN-RUIZ; ROS, 2018), a seleção e o uso dos livros didáticos e outros materiais curriculares por parte do corpo docente desse componente do currículo escolar (WEIR; CONNOR, 2009; DEVÍS-DEVÍS; MOLINA-ALVENTOSA; PEIRÓ-VELERT; KIRK, 2011; PEIRÓ-VELERT; MOLINAALVENTOSA; KIRK; DEVÍS-DEVÍS, 2015; TRAVÉ-GONZÁLEZ; POZUELOSESTRADA; TRAVÉ-GONZÁLEZ, 2017).

Não se pode partir da suposição, entretanto, de que os livros didáticos sempre atendam às necessidades do tempo presente, pois, por melhor que seja a produção, existirão limitações, tendo em vista que algumas questões têm pouco reconhecimento, como a complexidade, a interação disciplinar, a busca de relações, o conhecimento compartilhado, a visão globalizadora e a interconexão do conhecimento científico. Ressalta-se que, por vezes, o sujeito aprende com os livros didáticos que a cultura tem um caráter estático. "Que não há dialética, reconstrução crítica, e incerteza. Aprende que o saber se organiza desde a Academia, e se presenta tal como é elaborado na própria Academia: segmentado em disciplinas, especializado e organizado tematicamente (MARTÍNEZ-BONAFÉ, 2008, p. 63)". ${ }^{2}$

A padronização dos materiais curriculares impressos é um desafio que deverá ser enfrentado pela área de Educação Física. Conforme constatado nos achados dos estudos de Botelho e Neira (2014, p. 680), as imagens e os textos escritos, à medida que mostram uma noção hegemônica das práticas corporais e de seus praticantes, criam estereótipos e reforçam negativamente as diferenças, gerando "efeitos absolutamente contrários a uma educação democrática, ou seja, a uma educação que valorize de maneira igualitária todos os grupos que coabitam a sociedade contemporânea".

Observa-se que a representação da diversidade nos livros didáticos não tem configurado elementos que ocupam, em grande parte, a centralidade do processo educacional. Podem ser considerados, portanto, como dispositivos a serviço da transmissão cultural, de discursos e de leituras construídas e disseminadas de maneira quase hegemônica pelo sistema educacional, pois reproduzem imagens e cenários sociais capazes de reduzir a complexidade da realidade social. Diante 
dessa realidade, Rego-Agraso, Barreira-Cerqueiras e Mariño-Fernández (2018, p. 64) partem da afirmativa de que os materiais didáticos permeiam a construção discursiva da realidade social, além de reproduzir outras questões igualmente presentes nos materiais impressos - "São processos de invisibilidade ou discriminação associados a diferentes grupos ou grupos específicos e vinculados ao uso da linguagem e à reprodução de estereótipos".

Considerando que os livros didáticos apresentam uma linguagem poderosa para a reprodução de estereótipos de sexo, idade, cor ou raça, somatótipo e deficiência, uma vez que são transmitidas uma quantidade substancial de informações através de imagens que se filtram na consciência coletiva, necessitam de uma reflexão prévia.

O livro didático é um suporte sistematizador privilegiado dos conteúdos, muitas vezes cristalizando conceitos negativos e inferiorizantes, perpetuando discriminações. As imagens que aparecem nestes materiais podem ser portadoras de classificações que destacam negativamente pessoas ou grupos sociais, produzindo preconceitos e/ ou discriminações, sob os quais determinadas orientações ideológicas podem estar inculcadas na consciência coletiva dos leitores na ausência de reflexão.

Em estudos subsequentes, encontramos análises na representação de gênero (MOYA-MATA; ROS; BASTIDA; MENESCARDI, 2013; GONZÁLEZ-PALOMARES; ALTMANN; REY-CAO, 2015; GONZÁLEZ-PALOMARES; TÁBOAS-PAIS; REY-CAO, 2017; MOYA-MATA; RUIZ-SANCHIS; MARTIN-RUIZ; ROS, 2019b); na deficiência (MOYA-MATA et al., 2017; GONZALEZ-PALOMARES; REY-CAO, 2020); em representações corporais (MOYA-MATA; ROS; MENESCARDI; BASTIDA, 2014) e representações raciais (MOYA-MATA; ROS; BASTIDA; MENESCARDI, 2013; TÁBOAS-PAIS; REY-CAO, 2015).

Nesse sentido, as pesquisas sobre materiais didáticos, em nível nacional e internacional, demonstram a omissão de determinados atores sociais, sua invisibilidade e também a disseminação de estereótipos associados às categorias. Entretanto, também demonstram que existem investigações recentes que mostram avanços nesse sentido, destacando que esses estudos mostram uma diminuição ou mesmo a ausência de estereótipos em livros didáticos, tornando os indivíduos mais visíveis.

\section{MÉTODO}

O estudo empregou a Análise de Conteúdo (KRIPPENDORFF, 2003; NEUENDORF, 2017) das imagens contidas nos oito manuais de Educação Física produzidos pelas quatro editoras aprovadas no Programa Nacional do Livro e do Material Didático (BRASIL, 2017): Boreal, Terra Sul, FTD e Moderna.

A Tabela 1 mostra os títulos, volume e tiragem dos manuais usados para análise a partir de dados fornecidos pela Equipe do Livro Didático do Ministério da Educação (COARE/CGPLI/FNDE). Os livros do vol. 1 correspondem ao $1^{\circ}$ ciclo $\left(1^{\circ} \mathrm{e}\right.$ $2^{\circ}$ anos) e os do Vol. 2 , ao $2^{\circ}$ ciclo ( $3^{\circ}$ ao $5^{\circ}$ ano). 
Tabela 1 - Manuais selecionados para obter amostras das imagens

\begin{tabular}{ccc}
\hline \multirow{2}{*}{ Editora } & Título & $\begin{array}{c}\text { Quantidade de } \\
\text { exemplares distribuídos }\end{array}$ \\
\hline \multirow{2}{*}{ Terra Sul } & Manual do Professor para a Educação Física. Vol 1. & 18.318 \\
& Manual do Professor para a Educação Física. Vol 2. & 29.158 \\
\hline \multirow{2}{*}{ Boreal } & Práticas Corporais e a Educação Física Escolar. Vol 1. & 19.832 \\
& Práticas Corporais e a Educação Física Escolar. Vol 2. & 31.345 \\
\hline \multirow{2}{*}{ FTD } & Encontros Educação Física. Vol 1. & 40.858 \\
& Encontros Educação Física. Vol 2. & 62.470 \\
\hline \multirow{2}{*}{ Moderna } & Práticas Corporais - Educação Física. Vol 1. & 54.282 \\
& Práticas Corporais - Educação Física. Vol 2. & 84.153 \\
\hline
\end{tabular}

Fonte: Elaborada pelos autores com dados da pesquisa.

Do total de imagens dos oito manuais, apenas 854 foram incluídas no estudo por conterem pessoas, excluindo as imagens em que o tipo de atividade física que realizavam não foi distinguido.

Para o levantamento de dados foi utilizado como instrumento de análise da diversidade um sistema de cinco variáveis, subdividido em categorias: 1) agrupamento por sexo (homem/grupo de homens, mulher/grupo de mulheres, homem e mulher (par)/grupo misto); 2) ciclo de vida (infância, adolescência/juventude, adulto, várias); 3) cor ou raça (brancos, pardos, pretos, outras); 4) somatótipo (ectomorfo, mesomorfo, endomorfo); e 5) deficiência (física, sensorial, sem deficiência) (adaptado de MOYAMATA et al., 2018).

Para a análise estatística dos dados foi utilizado o software SPSS v. 26.0 (IBM SPSS Statistics Inc. Chicago, IL, EUA). Foram realizadas análises descritivas para obter frequências e porcentagens dos tipos de imagens, bem como das variáveis sobre a diversidade, apresentadas pelas pessoas das imagens estudadas. Por outro lado, foram realizados testes não paramétricos para saber se existem diferenças significativas nas imagens em relação às variáveis sobre a diversidade. Especificamente, foram realizados testes do Xis ao quadrado de independência para descobrir se existem diferenças significativas segundo o sexo, a idade, a cor ou a raça, o somatótipo ou a deficiência, representadas pelas pessoas nas ilustrações. Assim, foram estudados os resíduos padronizados corrigidos $\pm 1,96$ para saber em quais categorias essas diferenças são encontradas, e se incluiu o estatístico $V$ de Cramer para saber o tamanho do efeito.

\section{RESULTADOS}

Nas imagens dos manuais do professor de Educação Física predominam os desenhos $(54,4 \%)$; na sequência, as fotografias $(43,2 \%)$ e as pinturas $(2,3 \%)$. Constata-se que o maior número de imagens analisadas é proveniente da Editora Terra Sul (35,8\%) e o menor número procede da Editora Boreal (16,2\%). A Tabela 2 mostra a variação desses tipos de imagens de acordo com as editoras. 
Tabela 2 - Descrição da amostra de imagens por editoras e volumes

\begin{tabular}{cccccc}
\hline \multirow{2}{*}{ Editoras } & Volume & $\begin{array}{c}\text { Número de } \\
\text { imagens por livro }\end{array}$ & Desenhos & Fotografias & Pinturas \\
\cline { 3 - 6 } & & $\mathbf{n}(\%)$ & $\mathbf{n}(\%)$ & $\mathbf{n}(\%)$ & $\mathbf{n}(\%)$ \\
\hline Terra Sul & 1 & $95(11.1)$ & $89(10.4)$ & $4(0.4)$ & $2(0.2)$ \\
$(\mathrm{n}=306,35.9 \%)$ & 2 & $211(24.8)$ & $149(17.4)$ & $58(6.8)$ & $4(0.4)$ \\
\hline Boreal & 1 & $78(9.1)$ & $24(2.8)$ & $53(6.2)$ & $1(0.1)$ \\
$(\mathrm{n}=139,16.2 \%)$ & 2 & $61(7.1)$ & $27(3.2)$ & $31(3.6)$ & $3(0.3)$ \\
\hline FTD & 1 & $74(8.7)$ & $16(1.8)$ & $58(6.8)$ & $0(0)$ \\
$(\mathrm{n}=161,18.9 \%)$ & 2 & $87(10.2)$ & $16(1.8)$ & $71(8.3)$ & $0(0)$ \\
\hline Moderna & 1 & $95(11.1)$ & $55(6.4)$ & $39(4.5)$ & $1(0.1)$ \\
$(\mathrm{n}=248,29 \%)$ & 2 & $153(17.9)$ & $89(10.4)$ & $55(6.4)$ & $9(1)$ \\
\hline TOTAL DE IMAGENS & $854(100)$ & $465(54.4)$ & $369(43.2)$ & $20(2.3)$ \\
\hline
\end{tabular}

Os livros do vol. 1 correspondem ao $1^{\circ}$ ciclo ( $1^{\circ}$ e $2^{\circ}$ anos), e os do Vol. 2 , ao $2^{\circ}$ ciclo ( $3^{\circ}$ ao $5^{\circ}$ ano).

Fonte: Elaborada pelos autores com dados da pesquisa.

A Tabela 3 mostra a caracterização das 854 imagens analisadas de acordo com as variáveis sobre a diversidade consideradas no estudo. As porcentagens de cada uma dessas variáveis indicam que, globalmente, predominam nos manuais imagens de agrupamento misto sobre o sexo (48,5\%), especificamente de crianças $(61,4 \%)$, com corpos ectomorfos $(79,8 \%)$, de cor ou raça branca $(44,3 \%)$ e sem deficiências $(90,9 \%)$.

Tabela 3 - Caracterização das imagens segundo as variáveis do estudo e editoras

\begin{tabular}{|c|c|c|c|c|c|c|}
\hline & Global & Terra Sul & Boreal & FTD & Moderna & n \\
\hline & n (\%) & n (\%) & n (\%) & n (\%) & n (\%) & p \\
\hline \multicolumn{7}{|l|}{ Sexo-agrupamento } \\
\hline Homem/Grupo de homens & $248(30.7)$ & $76(25.4)$ & $38(31.9)$ & $33(22.1)$ & $101(42.1)$ & \multirow{3}{*}{$<.001$} \\
\hline Mulher/Grupo de mulheres & $168(20.8)$ & $40(13.4)$ & $28(23.5)$ & $27(18.1)$ & $73(30.4)$ & \\
\hline Homem e mulher/Grupo Misto & $391(48.5)$ & $183(61.2)$ & $53(44.5)$ & $89(59.7)$ & $66(27.5)$ & \\
\hline \multicolumn{7}{|l|}{ Ciclo de vida } \\
\hline Infância & $492(61.4)$ & $219(74.5)$ & $86(71.7)$ & $97(63)$ & $90(38.6)$ & \multirow{4}{*}{$<.001$} \\
\hline Adolescência/Juventude & $214(26.7)$ & $39(13.3)$ & $18(15)$ & $32(20.8)$ & $125(53.6)$ & \\
\hline Adulto & $8(1)$ & $1(0.3)$ & $1(0.8)$ & $4(2.6)$ & $2(0.9)$ & \\
\hline Várias & $87(10.9)$ & $35(11.9)$ & $15(12.5)$ & $21(13.6)$ & $16(6.9)$ & \\
\hline \multicolumn{7}{|l|}{ Somatótipo } \\
\hline Ectomorfo & $595(79.8)$ & $234(88.6)$ & $103(88.8)$ & $120(88.2)$ & $138(60.8)$ & \multirow{3}{*}{$<.001$} \\
\hline Mesomorfo & $148(19.8)$ & $30(11.4)$ & $13(11.2)$ & $16(11.8)$ & $89(39.2)$ & \\
\hline Endomorfo* & $3(0.4)$ & 1 & 0 & 1 & 1 & \\
\hline \multicolumn{7}{|l|}{ Cor ou Raça } \\
\hline Brancos & $362(44.3)$ & $109(36.5)$ & 72 (53.3) & $80(51.3)$ & $101(44.5)$ & \multirow{4}{*}{$<.001$} \\
\hline Pardos & $52(6.4)$ & $12(4)$ & $9(6.7)$ & $11(7.1)$ & $20(8.8)$ & \\
\hline Negros & $54(6.6)$ & $16(5.4)$ & $10(7.4)$ & $4(2.6)$ & $24(10.6)$ & \\
\hline Outras & $349(42.7)$ & $162(54.2)$ & $44(32.6)$ & $61(39.1)$ & $82(36.1)$ & \\
\hline \multicolumn{7}{|l|}{ Deficiência } \\
\hline Física & $36(4.6)$ & $16(5.6)$ & $0(0)$ & $7(5)$ & $13(5.7)$ & \multirow{3}{*}{.024} \\
\hline Sensorial & $35(4.5)$ & $18(6.3)$ & $1(0.8)$ & $8(5.8)$ & $8(3.5)$ & \\
\hline Sem deficiência & $705(90.9)$ & $253(88.2)$ & $120(99.2)$ & $124(89.2)$ & $208(90.8)$ & \\
\hline
\end{tabular}

Em negrito, os resíduos padronizados corrigidos \pm 1.96 .

* Esta categoria não foi considerada na análise estatística por somatótipo.

Fonte: Elaborada pelos autores com dados da pesquisa. 
A seguir, os resultados das imagens são apresentados de acordo com diversas variáveis sociodemográficas nas quatro editoras analisadas. Em relação ao sexo-agrupamento das pessoas que aparecem nas imagens analisadas, existem diferenças significativas, dependendo da editora contemplada $\left(X^{2}{ }_{(6)}=72.021 ; p\right.$ $<0.001 ; V=0.211$ ) (Tabela 3). Especificamente, os resíduos padronizados corrigidos indicam que as diferenças ocorrem entre a Editora Moderna, que é a que apresenta a maior porcentagem de imagens que representam homens $(42,1 \%)$, em relação a Terra Sul e FTD, que são os mínimos (25,4\% e 22,1\%, respectivamente). Porém, Moderna também é a que contém o maior número de imagens que representam mulheres fazendo atividade física (30,4\%), em comparação com a Terra Sul $(13,4 \%)$. Por outro lado, enquanto Terra Sul e FTD preferem, em sua maioria, mostrar imagens que representem grupos mistos (61,2\% e $59,7 \%$, respectivamente), Moderna o faz apenas em $27,5 \%$ das imagens, optando mais por imagens que contemplem homens e mulheres separadamente $(72,5 \%)$.

Em relação aos diferentes tipos de idade das pessoas que aparecem nas imagens contempladas neste estudo (Tabela 3), também se observam diferenças significativas entre as editoras $\left(X^{2}{ }_{(9)}=131.763 ; p<0.001 ; V=0.234\right)$. Os resíduos padronizados corrigidos indicam diferenças em algumas categorias. Em relação à categoria de imagens que representam as pessoas na infância, vemos diferenças entre as Editoras Terra Sul e Boreal (nas quais praticamente três em cada quatro imagens incluem meninos ou meninas no ciclo de vida que corresponde à infância) e Moderna, na qual apenas $38,6 \%$ incluem imagens com crianças nesse ciclo de vida. No entanto, as imagens de adolescentes são predominantes nos livros da Editora Moderna, com $53,6 \%$ de suas imagens dedicadas a esta etapa, em comparação com Terra Sul, que dedica $13,3 \%$ e $15 \%$ da Boreal. Por outro lado, é a Editora FTD que inclui a maior porcentagem de imagens nas quais os adultos e idosos aparecem $(2,6 \%)$.

No que diz respeito às imagens que representam as pessoas segundo seu somatótipo, ressalta-se que apenas três imagens representam pessoas com somatótipo endomórfico, o que representa $0,4 \%$ do total. Por esse motivo, essa categoria foi descartada para a análise. Ao comparar as imagens com os somatótipos ectomórfico e mesomórfico, foram observadas diferenças significativas entre as editoras estudadas $\left(X_{(3)}^{2}=76.245 ; p<0.001 ; V=0.320\right)$. De acordo com os resíduos padronizados corrigidos, exibido na Tabela 3, pode-se observar diferenças significativas entre todas as editoras. Especificamente, enquanto FTD, Boreal e Terra Sul representam uma proporção maior (88\%) de pessoas com um somatótipo ectomorfo, Moderna só faz $60,8 \%$ das vezes. Neste sentido, Moderna apresenta uma distribuição um pouco mais moderada, sendo a Editora que apresenta valores mais equilibrados na diversidade corporal em relação às demais.

Em relação a cor ou raça das pessoas representadas nas imagens estudadas, observam-se na Tabela 3 diferenças significativas entre as quatro editoras $\left(\mathrm{X}^{2}{ }_{(9)}=\right.$ 38.552; $p<0.001 ; V=0.125)$. Como indicam os resíduos padronizados corrigidos, nas imagens que representam pessoas brancas, as diferenças são entre a Editora Boreal, que é a que apresenta a maior porcentagem dessas imagens $(53,3 \%)$; e a 
Terra Sul, a que apresenta a menor porcentagem de imagens (36,5\%). Quanto às imagens que representam pessoas pardas, apenas a Editora Terra Sul é significativa, sendo a que apresenta o menor percentual de imagens publicadas de pessoas dessa cor ou raça (apenas 4\%). Em relação às imagens que incluem pretos, as diferenças são encontradas entre as Editoras Moderna, que publica o maior percentual $(10,6 \%)$ em relação à $F T D$, que é a que menos as inclui em seus livros (2,63\%). Nas imagens que representam pessoas de outra cor ou raça não contempladas nas categorias anteriores, as diferenças são entre Terra Sul (que é a que apresenta a maior porcentagem com 54,2\%) e Boreal e Moderna (que são as que apresentam a menor porcentagem, 32,6\% e 36,1\% respectivamente). De qualquer forma, é a Terra Sul que apresenta uma distribuição mais equitativa de imagens, de acordo com a cor ou raça das pessoas representadas nos manuais.

Por último, o estudo levou em consideração se as imagens apresentam ou não deficiência (física e sensorial). Em geral, na maioria das editoras, entre 88,2\% e $99,2 \%$ das imagens representam pessoas sem deficiência. No entanto, há diferenças significativas entre as duas editoras com percentuais mais distantes quanto à representação da deficiência $\left(X_{(6)}^{2}=14.545 ; p<0.05 ; \mathrm{V}=0.097\right)$. Enquanto a Editora Terra Sul se apresenta como a que mais reúne imagens com pessoas com deficiência física $(5,6 \%)$ e sensorial $(6,3 \%)$, a Boreal se destaca por não incluir imagens com pessoas com deficiência física $(0 \%)$ e deficiência sensorial $(0,8 \%)$.

\section{DISCUSSÕES}

Os resultados gerais da análise dos manuais de Educação Física para professores apresentam, predominantemente, desenhos de crianças, em agrupamentos mistos, com corpos ectomórficos, de cor ou raça branca e sem deficiências. O predomínio de desenhos nas imagens dos livros didáticos analisados em relação às fotografias e pinturas coincide com o estudo de Moya-Mata et al. (2017), o que produz um processo de infantilização na educação.

Em relação à representação das personagens, verifica-se uma mudança de tendência no sentido de uma aparência mais equitativa de homens e mulheres através de agrupamentos mistos nas imagens dos livros brasileiros, diferenciando das imagens predominantemente masculinas nos estudos dos livros portugueses ou espanhóis (GOMES et al., 2008; MOYA-MATA; ROS; BASTIDA; MENESCARDI, 2013; GONZÁLEZ-PALOMARES; ALTMAN, REY-CAO, 2015; MARTÍNEZ-BELLO; MOLINAGARCÍA, 2016; GONZÁLEZ-PALOMARES; TÁBOAS-PAIS; REY-CAO, 2017; MOYAMATA; RUIZ-SANCHIS; MARTIN-RUIZ; ROS, 2019b), sendo a presença feminina nos manuais muito escassa (SÁNCHEZ-HERNÁNDEZ; MARTOS-GARCÍA; LÓPEZNAVAJAS, 2017). Essas diferenças são provavelmente devido ao desaparecimento legal das salas de aula separadas por sexo há relativamente pouco tempo (década de 1990) no Brasil, embora essas práticas não tenham desaparecido totalmente.

Em algumas instituições, o professorado de Educação Física ainda planeja atividades distintas para meninas e meninos, sendo que a separação geralmente está justificada por determinadas concepções das possibilidades do corpo diante do 
movimento (DORNELLES; FRAGA, 2009). De qualquer forma, a proporcionalidade de imagens é fundamental, pois a partir da análise da participação de meninos e meninas em diversas práticas corporais no ambiente escolar, constata-se que a desigualdade de participação nas diferentes práticas ainda não está superada, "[...] elas ocorrem a partir de concepções generalizadas de corpo e habilidades físicas, que colocam e consideram discursivamente as meninas como menos hábeis quando comparadas com os meninos" (UCHOGA; ALTMANN, 2016, p. 169).

As crianças são as pessoas que mais aparecem nas imagens dos livros de Educação Física dos professores, apresentando os maiores percentuais, em três das quatro editoras analisadas. As imagens da infância predominam supostamente porque os livros são voltados para os estágios escolares da infância - anos iniciais da Educação Básica -; coincidindo com estudos anteriores (DEVÍS-DEVÍS, 2012; MARTÍNEZ-BELLO; MOLINA-GARCÍA, 2016; MOYA-MATA; RUIZ-SANCHIS; MARTIN-RUIZ; ROS, 2019b), com adultos sendo sub-representados e pessoas mais velhas praticamente invisíveis.

No entanto, quase não há imagens de professores de Educação Física, considerando que os manuais são dirigidos especificamente a esse público. Como as imagens representam este grupo profissional, permitem, por um lado, saber quais as imagens se projetam deste componente curricular, e, por outro lado, moldar nos leitores a sua percepção sobre a área do conhecimento (MOYA-MATA et al., 2017). Esta representação também pode mostrar diferentes papéis dentro de sua atividade de ensino como participante (envolvido(a) ativamente nas atividades junto com os alunos) e/ou observador(a) e avaliador(a) (verifica as atividades à distância, sem muito contato, anotando as aprendizagens). Além disso, pode mostrar diferentes estilos de ensino, práticas docentes ou vestimentas que não serão possíveis devido à ausência de imagens.

Segundo o somatótipo nos manuais do professor analisados, representam predominantemente o estereótipo corporal ectomorfo, coincidindo com estudos anteriores (MOYA-MATA; ROS; MENESCARDI; BASTIDA, 2014; MOYA-MATA; ROS; PEIRATS, 2018), sendo mais escassas as imagens em que aparecem outra tipologia corporal, endomorfo, por exemplo. Estas representações podem configurar a exclusão de alunos com sobrepeso e/ou obesos, já que praticamente não aparecem nas imagens dos livros analisados, limitando a superação de inúmeras práticas preconceituosas e/ou discriminatórias, como ideais de beleza padronizados. É importante considerar a forma, a estrutura ou a morfologia corporal dos sujeitos das imagens porque influencia a representação mental do que é considerado socialmente adequado em quem os vê (MOYA-MATA; ROS; MENESCARDI; BASTIDA, 2014).

Em estudos similares, embora em outra especificidade cultural, pesquisadores evidenciaram que a cor ou raça branca prevalece sobre as demais (MOYA-MATA; ROS; BASTIDA; MENESCARDI, 2013; TÁBOAS-PAIS; REY-CAO, 2015; MOYAMATA; ROS; PEIRATS, 2018). Esta omissão da diversidade racial nos livros didáticos demonstra uma visão tendenciosa, além da ausência desse grupo social na participação das práticas corporais ser, também, uma forma de discriminação, que contrasta com o quadro atual legislativo em que os manuais didáticos são elaborados. 
Um estudo de Táboas-Pais e Rey-Cao (2015), com vistas a analisar a representação da cor ou raça nas imagens publicadas em livros espanhóis de Educação Física, constatou que o tipo de atividade física, o campo, o espaço e o nível de competência variam de acordo com a cor ou raça. Além disso, as mensagens transmitidas pelas imagens não facilitam a construção de identidades raciais diversificadas e compartilhadas.

Portanto, a baixa representatividade de pessoas negras e pardas nos livros didáticos de todas as editoras é problemática, uma vez que mais da metade da população brasileira se autodeclara como parda ou negra. Isto quer dizer que a baixa diversidade racial representada nas imagens estudadas precisa ser revista, com uma distribuição mais equitativa. Segundo Pesquisa Nacional por Amostra de Domicílios Contínua, realizada pelo Instituto Brasileiro de Geografia e Estatística (IBGE), constatou-se que, entre 2012 e 2016, a participação percentual dos brancos na população do país caiu (de $46,6 \%$ para $44,2 \%$ ), enquanto a participação dos pardos aumentou (de $45,3 \%$ para $46,7 \%$ ), assim como a dos pretos (de $7,4 \%$ para $8,2 \%$ ) (IBGE, 2016). Os brancos representavam mais da metade da população no Censo Demográfico de 2010, porém, naquele ano, verificou-se que pretos e pardos ultrapassaram a população branca. Esta é uma tendência verificável ao longo do tempo, decorrente da miscigenação e aumento da autodeclaração de pretos - mais pessoas se identificam e/ou se reconhecem como pretas.

Por último, a baixa presença de pessoas com deficiência nas imagens dos manuais analisados indica uma lacuna a ser superada. Trata-se de um tema continuamente ausente da pauta de interesses dos pesquisadores que interrogam o lugar das minorias políticas nos livros didáticos brasileiros (BARROS, 2013), além de ser uma recomendação do relatório do Fundo das Nações Unidas para Infância (UNICEF, 2013), em que a representação de crianças com deficiência deve estar presente em livros didáticos ou outros materiais curriculares, para evitar preconceitos sociais deste grupo. Embora estudos sobre imagens e deficiência em livros didáticos ainda sejam escassos em Educação Física, todos coincidem na sub-representação de pessoas com deficiência fazendo atividade física (HARDIN; HARDIN, 2004; HARDIN, 2007; GONZALEZ-PALOMARES; REY-CAO; TABOAS-PAIS, 2015; MOYAMATA et al., 2017; MOYA-MATA; ROS; PEIRATS, 2018).

Concretamente, no estudo exploratório de livros didáticos de Educação Física no Brasil, González-Palomares; Rey-Cao; Táboas-Pais (2015) constataram que as pessoas com deficiência geralmente estão representadas em práticas esportivas realizadas em contextos competitivos de elevado nível de profissionalismo. Assim, a participação desse grupo é limitada a certas práticas corporais não inclusivas e distantes de contextos educacionais. O estudo também revelou que mulheres com deficiência são minimamente representadas nas imagens dos livros didáticos, e que os tipos de deficiência apresentados nas imagens estão longe do estereótipo tradicional, que associa a deficiência ao uso da cadeira de rodas. Embora a legislação educacional determine a inclusão desse grupo social nas escolas, a representação de crianças com deficiência nos livros didáticos ainda é modesta.

A inserção da pessoa com deficiência na escola regular brasileira pressupõe mudanças nos recursos didáticos para ocorrer, efetivamente, a inclusão. Assim, os 
materiais curriculares impressos necessitam ser constantemente revisados, pois, ao veicular imagens de pessoas com diversidade funcional, contribuem para a construção de representações positivas ou negativas sobre esses sujeitos.

Ante o exposto, verifica-se a necessidade de proposições capazes de problematizar a produção das diferenças com relação às práticas corporais, compreendidas como "textos da cultura, impregnados pelos marcadores de classe, gênero, etnia, religião, etc." (NEIRA, 2018, p. 222), sendo fundamental identificar e superar representações pejorativas, de repúdio e/ou exaltação a certas manifestações, com base nos seus representantes, grupos sociais que as criaram e recriaram. Entretanto, entendemos que o manual do professor de Educação Física tem mais a oferecer em benefícios para o desenvolvimento das aulas do que as possíveis dificuldades que possam se apresentar, considerando o processo formativo, o tempo de adaptação do professor ao material, e também por esse material não fazer parte do cotidiano de suas aulas (BARROSO; DARIDO, 2017).

\section{CONCLUSÕES}

Em geral, as editoras contemplam imagens que focalizam grupos mistos, embora quando apenas um gênero é incluído, as de homens prevalecem sobre as de mulheres. Predominam imagens que representam pessoas na infância, somatótipo do tipo ectomórfico, cor ou raça branca, e diversidade semifuncional. Existem diferenças entre as editoras, destacando-se a Terra Sul como a que apresenta maior diversidade em suas imagens em termos de gênero, cor ou raça e diversidade funcional. Moderna destaca-se por apresentar um maior equilíbrio entre as faixas etárias representadas nas suas imagens e no somatótipo.

Esses resultados permitem concluir que as obras analisadas precisam avançar quando o assunto é a valorização da diversidade. Realça-se, portanto, a constante revisão/atualização dos manuais pelas editoras e a necessidade de promover uma cultura cada vez mais inclusiva.

Ao se deparar com tais indicadores, é necessário observar que o Brasil é um país caracterizado pela acentuada diversidade cultural e profundas assimetrias sociais, e que, ao longo de sua história, naturalizou desigualdades educacionais em relação ao acesso à escola, à permanência dos estudantes e ao seu aprendizado, sendo conhecido o enorme desiquilíbrio entre os grupos de estudantes definidos por cor ou raça, sexo e condição socioeconômica de suas famílias (BRASIL, 2018).

Esses aspectos são suficientes para justificar a elaboração de materiais curriculares capazes de atender as necessidades e os interesses dos estudantes, assim como suas identidades (linguísticas, étnicas e culturais). Entretanto, compreende-se que os materiais curriculares impressos brasileiros necessitam ampliar as possibilidades em relação à diversidade no interior do currículo, em uma perspectiva multicultural. 


\section{REFERÊNCIAS}

ACASO, María; NUERE, Silvia. El currículum oculto visual: aprender a obedecer a través de la imagen. Arte, individuo y sociedad, v. 17, p. 207-220, 2005. Disponível em: https:// dialnet.unirioja.es/servlet/articulo?codigo=1173004. Acesso em: 8 out. 2019.

AMARAL, Lucas Vieira; MEDEIROS, Roberto Carneiro de Medeiros; SOUZA, JÚNIOR Marcílio; Adriana Letícia Torres Rosa; MELO, Marcelo Soares Tavares de. Textos didáticos em educação física: percepção docente sobre elaboração e utilização. Revista Brasileira de Educação Física e Esporte, v. 35, p. 119-128, 2021. Disponível em: https://www. revistas.usp.br/rbefe/article/view/184427. Acesso em: 21 jan. 2021.

BARROS, Alessandra Santana Soares. Representações e significados da deficiência nos livros didáticos de Ciências do PNLD 2007. Ser Social, v. 15, p. 75-91, 2013. Disponível em: https://periodicos.unb.br/index.php/SER Social/article/view/13035. Acesso em: 20 jan. 2020.

BARROSO, Andre Luís Ruggiero; DARIDO, Suraya Cristina. O livro didático na educação física escolar: visão de professores e alunos. Pensar a Prática, v. 20, n. 3, p. 488-502, 2017. Disponível em: https://www.revistas.ufg.br/fef/article/view/42219. Acesso em: 21 jan. 2021.

BOTELHO, Rafael Guimarães; NEIRA, Marcos Garcia. Análisis de libros de texto en Brasil y en España: una introducción al tema en el área de Educación Física. Movimento, v. 20, n. 2, p. 659-685, abr./jun. de 2014. DOI: https://doi.org/10.22456/1982-8918.41791

BRASIL. Ministério da Educação. Secretaria de Educação Básica. Base Nacional Comum Curricular. Brasília, DF: MEC, 2018. Disponível em: http://basenacionalcomum.mec.gov.br/. Acesso em: 4 ago. 2019.

BRASIL. Decreto n 9.099, de 18 de julho de 2017. Dispõe sobre o programa nacional do livro e do material didático. Brasília, DF: Presidência da República, 2017. Disponível em: http://www.planalto.gov.br/ccivil_03/_ato2015-2018/2017/decreto/D9099.htm. Acesso em: 21 jan. 2021.

CACHIA, Romina; FERRARI, Anusca. Creativity in schools: a survey of teachers in Europe. Luxemburgo: Publications Office of the European Union, 2010.

DEVÍS-DEVÍS, José.; MOLINA-ALVENTOSA, Juan Pedro; PEIRÓ-VELERT, Carmen; KIRK, David. Selection of printed curriculum materials in physical education: Recontextualizing pedagogical knowledge. European Physical Education Review, v. 17, n. 1, p. 19-34, 2011.

DEVÍS-DEVÍS, José; PEIRÓ-VELERT, Carmen; MOLINA-ALVENTOSA, Juan Pedro; VILLAMÓN, Miguel; ANTOLÍN, Luis; RODA, Fernando. Los materiales curriculares impresos en Educación Física: classificación, usos e investigación. Movimento, v. 7, n. 15, p. 119136, 2001. DOI: https://doi.org/10.22456/1982-8918.2627

DEVÍS-DEVÍS, José. La investigación sociocrítica en la Educación Física. Estudios Pedagógicos, v. XXXVIII, número especial 1, p. 125-153, 2012. Disponível em: <http://www. redalyc.org/articulo.oa?id=173525520017>. Acesso em: 29 ago. 2019.

DORNELLES, Priscila Gomes; FRAGA, Alex Branco. Aula mista versus aula separada? Uma questão de gênero recorrente na Educação Física escolar. Revista Brasileira de Docência, Ensino e Pesquisa em Educação Física, n. 1, p. 141-56, 2009.

GOMES, Paula Botelho; SILVA, Paula; QUEIRÓS, Telma Maria Gonçalves; CAETANO, Silvia. Manuais de Educação Física: em rota de colisão com gênero, diversidade e cidadania? In: HENRIQUES, Fernanda (org.). Género, diversidade e cidadania. Évora: Edições Colibri, 2008. p. 89-101. 
GONZÁLEZ-PALOMARES, Alba; ALTMANN, Helena; REY-CAO, Ana. Estereótipos de gênero nas imagens dos livros didáticos de Educação Física do Brasil. Movimento, v. 21, n. 1, p. 219-232, jan./mar. de 2015. DOI: https://doi.org/10.22456/1982-8918.47114

GONZÁLEZ-PALOMARES, Alba; REY-CAO, Ana. The representation of disability in physical education textbooks in Spain. Sport in Society, v. 20, n. 1, p. 1-19, out. 2020. Disponível em: https://www.tandfonline.com/doi/ epub/10.1080/17430437.2020.1828355?needAccess=true. Acesso em: 16 out. 2020.

GONZÁLEZ-PALOMARES, Alba; REY-CAO, Ana; TABOAS-PAIS, María Inés. La discapacidad en la enseñanza pública: estudio exploratorio de los libros de texto de Educación Física de Brasil. Saúde e Sociedade, v. 24, n. 4, p. 1316-1331, dez. 2015. Disponível em: http://www.scielo.br/scielo.php?script=sci arttext\&pid=S010412902015000401316\&lng=en\&nrm=iso. Acesso em: 03 Dez. 2020.

GONZÁLEZ-PALOMARES, Alba; TÁBOAS-PAIS, María; REY-CAO, Ana. La cultura corporal en función del género: análisis de los libros de texto de educación física de secundaria publicados durante la Ley Orgánica de Educación. Educación XX1, v.20, n. 1, p. 141162, out. 2017. Disponível em: http://revistas.uned.es/index.php/educacionXX1/article/ view/17506/18891. Acesso em: 18 dez. 2019.

HARDIN, Brent. Physical Education textbooks and portrayals of disability. Palaestra, v. 23, n. 4, p. 6-8, 2007. Disponível em: https://js.sagamorepub.com/palaestra/issue/view/837. Acesso em: 16 out. 2020.

HARDIN, Brent.; HARDIN, Marie. Distorted pictures: images of disability in physical education textbooks. Adapted Physical Activity Quarterly, v. 21, n.4, p. 399-413, 2004. Disponível em: https://journals. humankinetics.com/view/journals/apaq/21/4/article-p399.xml. Acesso em: 16 out. 2020.

IBGE - INSTITUTO BRASILEIRO DE GEOGRAFIA E ESTATÍSTICA. Pesquisa Nacional por Amostra de Domicílios Contínua 2016. Rio de Janeiro, 2017. Disponível em: https:// www.ibge.gov.brl. Acesso em: 18 jan. 2020.

JANEMALM, Lucas; QUENNERSTEDT, Mikael; BARKER, Dean. What is complex in complex movement? A discourse analysis of conceptualizations of movement in the Swedish physical education curriculum. European Physical Education Review, v. 25, n.4, p. 11461159, 2019.

KRIPPENDORFF, Klaus. Content analysis: an introduction to its methodology. Thousand Oaks, CA: Sage, 2003.

LOUREIRO, Marcus Wagner Antunes; MOREIRA, Kênia Hilda. Livros didáticos de educação física: um balanço da produção acadêmica. Educação e Pesquisa, v. 46, p. 1-19, 2020. Disponível em: https://www.revistas.usp.br/ep/article/view/169744._Acesso em: 29 jun. 2021.

MARTÍNEZ-BELLO, Vladimir.; MOLINA-GARCÍA, Javier. Representation of physical activity domains and sedentary behaviours in physical education textbooks: an image analysis.

South African Journal for Research in Sport, Physical Education and Recreation, v. 38, n. 2, p. 139-152, 2016.

MARTÍNEZ-BONAFÉ, Jaume. Los libros de texto como práctica discursiva. Revista de Sociología de la Educación (RASE), v. 1, n. 1, p. 62-73, jan. 2008. Disponível em: https:// ojs.uv.es/index.php/RASE/article/view/8537. Acesso em: 18 jan. 2020. 
MOLINA-ALVENTOSA, Joan Pere. El uso de materiales curriculares impresos en la Educación Física de la ESO en la Comunidad Valenciana. 2015. 594f. Tese (Doutorado em Educação Física e Esportes) - Faculdade de Ciências da Atividade Física e Esportes, Universidade de Valência, Valência-Espanha.

MOLINA-ALVENTOSA, Joan Pere; DEVÍS-DEVÍS, José; PEIRÓ-VELERT, Carmem. Materiales curriculares: classificación y uso em Educación Física. Pixel-bit. Revista de Medios y Educación, n. 33, p. 183-197, jul. 2008.

MOYA-MATA, Irene; RUIZ-SANCHIS, Laura; MARTIN-RUIZ, Julio; ROS, Concepción. La actividad física representada en los libros de texto de Educación Física en Educación Primaria. Movimento, v. 25, p. 1-13, jan./mar. de 2019a. DOI: https://doi.org/10.22456/1982$\underline{8918.89296}$

MOYA-MATA, Irene; RUIZ-SANCHIS, Laura; MARTIN-RUIZ, Julio; ROS, Concepción. Estereotipos de género en las imágenes que representan las actividades en el medio natural en los libros de Educación Física de Primaria. Cultura Ciencia Deporte (CDD), ano 15, v. 14, p. 15-23, 2019b. Disponível em: <https://ccd.ucam.edu/index.php/revista/article/ view/1222>. Acesso em: 08 out. 2019.

MOYA-MATA, Irene et al. Diseño, fiabilidad y validez de una herramienta para el análisis de las imágenes de los libros de texto de Educación Física. Retos: Nuevas Tendencias en Educación Física, Deporte y Recreación, n. 34, p. 240-246, 2018. Disponível em: <https:// recyt.fecyt.es/index.php/retos/article/view/59497>. Acesso em: 02 jul. 2019.

MOYA-MATA, Irene et al. La representación de la discapacidad en las imágenes de los libros de texto de Educación Física: ¿inclusión o exclusión? Retos: Nuevas Tendencias en Educación Física, Deporte y Recreación, n. 32, p. 88-95, 2017. Disponível em: <https:// dialnet.unirioja.es/servlet/articulo?codigo=6352281 >. Acesso em: 09 dez. 2019.

MOYA-MATA, Irene. Los libros de texto en Educación Física en la etapa de Educación Primaria: análisis de las imágenes y estereótipos. 2017. 283f. Tese (Doutorado em Pesquisa e Desenvolvimento) - Faculdade de Ciências da Atividade Física e Esporte, Universidade Católica de Valência San Vicente Mártir, Valência - Espanha.

MOYA-MATA, Irene; ROS, Concepción; BASTIDA, Ana Isabel; MENESCARDI, Cristina. Estereotipos de sexo y raza en las imágenes de los libros de texto de educación física en primaria. Retos: Nuevas Tendencias en Educación Física, Deporte y Recreación, n. 23, p. 14-18, mar. 2013. Disponível em: <https://recyt.fecyt.es/index.php/retos/article/ view/34560/18684>. Acesso em: 18 dez. 2019.

MOYA-MATA, Irene; ROS, Concepción; PEIRATS, José. ¿Qué representan las portadas de los libros de texto de Educación Física en Primaria? Retos: Nuevas Tendencias en Educación Física, Deporte y Recreación, n. 34, p. 295-299, 2018. Disponível em: <https:// dialnet.unirioja.es/servlet/articulo?codigo=6736322>. Acesso em: 08 out. 2019.

MOYA-MATA, Irene; ROS, Concepción; MENESCARDI, Cristina; BASTIDA, Ana Isabel. Estereotipos corporales en los libros de texto de Educación Física en Educación Primaria. Habilidad Motriz, n. 43, p. 25-32, 2014. Disponível em: <http://mobiroderic.uv.es/ handle/10550/54938? show=full>. Acesso em: 18 out. 2019.

MUNAKATA, Kazumi. O livro didático: alguns temas de pesquisa. Revista Brasileira de História da Educação, v. 12, n. 3, p. 179-197, set./dez. 2012. Disponível em: http://dx.doi. org/10.4322/rbhe.2013.008. Acesso em: 30 ago. 2019. 
MUNK-SVENDSEN, Annemari; TINGGAARD-SVENDSEN, Jesper. Contesting discourses about physical education: A critical discourse analysis of 20 textbooks used in physical education teacher education in Denmark. European Physical Education Review, v. 23, n. 4, p. 480-498, 2016.

NEIRA, Marcos Garcia. Incoerências e inconsistências da BNCC de Educação Física. Revista Brasileira de Ciências do Esporte, v. 40, n. 3, p. 215-223, 2018. Disponível em: https://doi.org/10.1016/..rbce.2018.04.001. Acesso em: 29 jun. 2021.

NEUENDORF, Kimberly. The content analysis guidebook. 2. ed. Los Angeles: SAGE, 2017.

PEIRÓ-VELERT, Carmen; MOLINA-ALVENTOSA, Joan Pere; KIRK, David; DEVÍS-DEVÍS, José. The Uses of Printed Curriculum Materials by Teachers during Instruction and the Social Construction of Pedagogic Discourse in Physical Education. Journal of Teaching in Physical Education, v. 34, n. 1, p. 18-35, 2015.

REGO-AGRASO, Laura; BARREIRA-CERQUEIRAS, Eva María; MARIÑO-FERNÁNDEZ, Raquel. The representation of social diversity in educational multimedia materials. Journal@ tic revista d'innovació educativa, n. 20, p. 63-71, jan./jun. 2018. Disponível em: https://ojs. uv.es/index.php/attic/article/view/12118. Acesso em: 08 out. 2019.

ROSSI, Tony; TINNING, Richard.; MCCUAIG, Louise Anne; SIRMA, Karen; HUNTER, Lisa. With the best of intentions: a critical discourse analysis of physical education curriculum materials. Journal of Teaching in Physical Education, v. 28, n. 1, p. 75-89, 2009.

SÁNCHEZ-HERNÁNDEZ, Núria; MARTOS-GARCÍA, Daniel; LÓPEZ-NAVAJAS, Ana. Las mujeres en los materiales curriculares: el caso de dos libros de texto de Educación Física. Revista Retos: nuevas tendencias en Educación Física, Deporte y Recreación, n. 32, p. 140-145, 2017. Disponível em: https://www.redalyc.org/pdf/3457/345751100028.pdf. Acesso em: 8 out. 2019.

SILVA, Igor Araujo da; PAULA, Carlos Felipe Cunha; FERNANDES, Isabella Perrotta Lemos; OLIVEIRA, Natalia Cristine Ramos de; ANACLETO, Francis Natally de Almeida. PNLD e a Educação Física: uma análise comparativa entre os componentes curriculares no ensino fundamental. Revista de Ensino, Educação e Ciências Humanas, v. 21, n. 1, p. 102-111, 2020. Disponível em: https://revista.pgsskroton.com/index.php/ensino/article/view/7631. Acesso em: 29 jun. 2021.

SILVA, Tomaz Tadeu. Documentos de identidad: una introducción a las teorías del currículo. 2 ed. Belo Horizonte: Autêntica Editorial, 1999.

TÁBOAS-PAIS, María Inés; REY-CAO, Ana. Racial representation in physical education textbooks for secondary schools: image content and perceptions held by students. SAGE Open, v. 5, n. 1, p. 1-11, jan./mar. 2015. Disponível em: https://journals.sagepub.com/doi/ full/10.1177/2158244015574972. Acesso em: $18 \mathrm{dez} .2019$.

TRAVÉ-GONZÁLEZ, Gabriel; POZUELOS-ESTRADA, Francisco José; TRAVÉ-GONZÁLEZ, Gabriel $(\mathrm{H})$. How teachers design and implement instructional materials to improve classroom practice. Intangible Capital (IC), v. 13, n. 5, p. 967-1043, 2017.

UCHOGA, Liane Aparecida Roveran; ALTMANN, Helena. Educação física escolar e relações de gênero: diferentes modos de participar e arriscar-se nos conteúdos de aula. Revista Brasileira de Ciências do Esporte, v. 38, n. 2, p. 163-170, jun. 2016. Disponível em: http:// www.scielo.br/pdf/rbce/v38n2/0101-3289-rbce-38-02-0163.pdf. Acesso em: 21 jan. 2020. 
UNICEF - FONDO DE LAS NACIONES UNIDAS PARA LA INFANCIA. Estado mundial de la infancia 2013: niños y niñas con discapacidad. Disponível em: https://www.unicef.org/ spanish/publications/files/SPANISH SOWC2013 Lo res.pdf. Acesso em: 03 Dez. 2020.

WEIR, Tony; CONNOR, Sean. The use of digital video in physical education. Technology, Pedagogy and Education, v. 18, n. 2, p. 155-171, 2009. 
Abstract: Image is an iconic language, with the power to transmit information, reproduce stereotypes and influence teachers. This study is about Physical Education teacher manuals designed in Brazil and approved in the National Teaching Book and Materials Program (BRASIL, 2017). Specifically, it analyses images of people in them to see if there are stereotypes related to bodily practices. An analysis of 854 images through Chi-Square independence tests revealed stereotypes related to bodily practices. The results show the predominance of mixed groups of children, with ectomorphic bodies, of white colour or race, and without disabilities. Therefore, although sex diversity is represented, the materials still favour reproduction of stereotypes and traditional hegemonic groups, perpetuating the invisibility of diversity in colour or race, bodies and people with disabilities.

Keywords: Teaching Materials. Physical Education. Body Image. Cultural diversity.

Resumen: La imagen es un lenguaje icónico con el poder de transmitir informaciones, reproducir estereotipos e influir en el profesor. Este estudio versa sobre los manuales del profesor de Educación Física elaborados en Brasil y aprobados en el Programa Nacional del Libro y del Material Didáctico (BRASIL, 2017). Concretamente, analiza las imágenes de personas que aparecen en estos manuales, con el fin de verificar si existen estereotipos relacionados con las prácticas corporales. Se llevó a cabo un análisis con 854 imágenes a través de pruebas Chi-Cuadrado de independencia que revelaron estereotipos relacionados con las prácticas corporales. Los resultados muestran el predominio de grupos mixtos de niños y niñas, con cuerpos ectomorfos, de color o raza blanca y sin discapacidad. Aunque la diversidad de sexos está representada, los materiales aún favorecen la reproducción de estereotipos y grupos hegemónicos tradicionales, perpetuando la invisibilidad de la diversidad de cuerpos, de color o de razas y de personas con discapacidad.

Palabras clave: Materiales de enseñanza. Educación Física. Imagen Corporal. Diversidad cultural. 


\section{LICENÇA DE USO}

Este é um artigo publicado em acesso aberto (Open Access) sob a licença Creative Commons Atribuição 4.0 Internacional (CC BY 4.0), que permite uso, distribuição e reprodução em qualquer meio, desde que o trabalho original seja corretamente citado. Mais informações em: https://creativecommons.org/licenses/by/4.0

\section{CONFLITO DE INTERESSES}

Os autores declararam que não existe nenhum conflito de interesses neste trabalho

\section{CONTRIBUIÇÕES AUTORAIS}

Alexandre Paulo Loro: Elaboração do projeto. Levantamento de bases teóricas. Interpretação de dados. Produção da redação, revisão e finalização.

Irene Moya-Mata: Contribuição na elaboração do projeto, revisão e edição.

Alexandra Valencia-Peris: Análise estatística, escrita - rascunho original, escrita revisão e edição.

Meire Aparecida Lóde Nunes: Elaboração do projeto, revisão e finalização. José Devís-Devís: Contribuição na elaboração do projeto e desenho, redação da versão original e versão final.

\section{FINANCIAMENTO}

O presente trabalho foi realizado com apoio da Coordenação de Aperfeiçoamento de Pessoal de Nível Superior - Brasil (CAPES) - Código de Financiamento 001. "This study was financed in part by the Coordenação de Aperfeiçoamento de Pessoal de Nível Superior - Brasil (CAPES) - Finance Code 001"

\section{COMO REFERENCIAR}

LORO, Alexandre Paulo; MOYA MATA, Irene; VALENCIA PERIS Alexandra; NUNES, Meire Aparecida Lóde; DEVÍS DEVÍS, José. A diversidade nas imagens dos manuais do professor de educação física no Brasil. Movimento (Porto Alegre), v.27, p.e27049, jan./dez. 2021. Disponível em: https://seer.ufrgs.br/ Movimento/article/view/112065. Acesso em: [dia] [mês abreviado]. [ano]. DOI: https://doi.org/10.22456/1982-8918.112065

\section{RESPONSABILIDADE EDITORIAL}

Alex Branco Fraga*, Elisandro Schultz Wittizorecki, Ivone Job*, Mauro Myskiw*, Raquel da Silveira*

*Universidade Federal do Rio Grande do Sul, Escola de Educação Física, Fisioterapia e Dança, Porto Alegre, RS, Brasil. 